\title{
Acute pneumonitis associated with low dose methotrexate treatment for rheumatoid arthritis: report of five cases and review of published reports
}

\author{
M R Hargreaves, A G Mowat, M K Benson
}

\begin{abstract}
Background Low dose methotrexate has become established in the treatment of refractory rheumatoid arthritis. Until recently it has been considered that the use of a low dose regimen ( $<20 \mathrm{mg}$ ) week) would avoid the pulmonary toxicity associated with the higher doses prescribed in malignant disease. Although initial experience with low dose methotrexate was encouraging, an increasing number of cases of an acute, life threatening pneumonitis are being reported in patients with refractory rheumatoid arthritis.
\end{abstract}

Patients Since 198443 patients with refractory rheumatoid arthritis have been established on low dose methotrexate in the Oxford Health District. Five of these patients have subsequently developed acute methotrexate induced pneumonitis. The clinical and radiological features of these cases are described and previous reports reviewed.

Results Five patients having low dose methotrexate treatment developed acute pneumonitis. Presentation was subacute and dominated by constitutional features. Respiratory symptoms developed insidiously but progressed rapidly with increasing dyspnoea associated with severe hypoxia. Chest radiographs were nonspecific, showing diffuse interstitial infiltration and alveolar shadowing. Microbiological investigation gave negative results. In all cases methotrexate was discontinued and high dose corticosteroids started, with rapid clinical and radiological improvement. After withdrawal of steroid both clinical and radiological resolution was maintained at follow up.

Conclusion Acute pneumonitis is an uncommon but serious adverse effect of low dose methotrexate treatment for refractory rheumatoid arthritis. The initial presentation is non-specific and a high index of suspicion is required as respiratory failure may develop rapidly. Management depends on exclusion of infection, withdrawal of methotrexate, and high dose corticosteroid treatment. Full supportive treatment is indicated as the prognosis in such patients is good.

The value of low dose methotrexate in the treatment of refractory rheumatoid arthritis is well established. ${ }^{1-3}$ Although pulmonary tox- icity associated with methotrexate is recognised, it has been considered that a low dose regimen may avoid such problems. ${ }^{4}$ Initial experience was encouraging but in 1983 the first cases of acute methotrexate induced pneumonitis were reported. ${ }^{56}$ Since then over 30 such cases have been published worldwide, reflecting increased enthusiasm for the earlier use of methotrexate in rheumatoid arthritis rather that its occasional use in refractory cases. We describe five further cases and review previous reports.

\section{Case reports}

PATIENT 1

In August 1988 a 47 year old woman with a 13 year history of seropositive rheumatoid arthritis was referred for investigation of dyspnoea. In March 1988, as a result of a sustained inflammatory exacerbation, she had been started on methotrexate $10 \mathrm{mg} /$ week (total dose $100 \mathrm{mg}$ ), which in conjunction with fenbufen resulted in a good therapeutic response. Three weeks before admission she developed a non-productive cough associated with general malaise and despite antibiotics became increasingly dyspnoeic.

On examination she was cyanosed and dyspnoeic at rest. Her temperature was $38.5^{\circ} \mathrm{C}$, pulse $140 / \mathrm{min}$ regular, and blood pressure $120 / 80 \mathrm{~mm} \mathrm{Hg}$. Examination of the chest indicated scattered inspiratory crepitations at the right base.

The haemoglobin concentration was 10.3 $\mathrm{g} / \mathrm{dl}$ and white blood cells $8.4 \times 10^{9} / 1$ eosinophilia. The erythrocyte sedimentation rate was $39 \mathrm{~mm}$ in the first hour. Arterial blood gas analysis (with an inspired oxygen concentration $\left(\mathrm{FIO}_{2}\right)$ of $21 \%$ ) showed that $\mathrm{pH}$ was $7 \cdot 47$, arterial carbon dioxide tension $\left(\mathrm{PaCO}_{2}\right) 4 \cdot 10$ $\mathrm{kPa}$, arterial oxygen tension $\left(\mathrm{PaO}_{2}\right) 5.26 \mathrm{kPa}$. The chest radiograph showed diffuse bilateral interstitial infiltrates (fig 1). Cultures of sputum and blood samples were negative and serological tests on convalescent phase serum showed no rise in titres of antibodies to atypical agents. Methotrexate was stopped. Ampicillin and erythromycin were administered intravenously.

Over the following 48 hours her condition deteriorated and a repeat chest radiograph showed increase interstitial shadowing (fig 1B). She was transferred to the medical intensive care unit, where she was electively intubated and ventilated before bronchoscopy. Bronchoalveolar lavage fluid showed no pathogens. Prednisolone $60 \mathrm{mg}$ daily was prescribed and over the subsequent 72 hours her condition 
Figure 1 Case 1: Radiological appearances (A) at admission; $(B) 48$ hours later; (C) at discharge 13 days later.
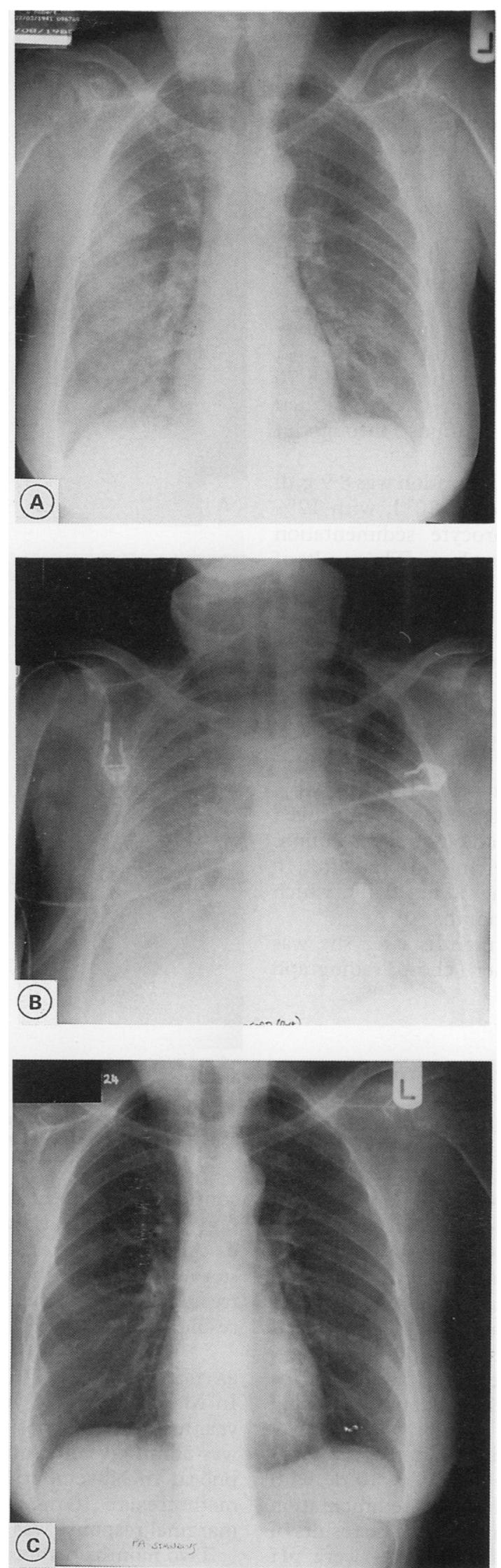

rapidly improved with resolution of the radiological changes.

She was discharged after 15 days with reducing doses of corticosteroids, which were tailed off over the following month. Her chest radiograph (fig 1C) and arterial blood gases were normal. When reviewed at six months she had active joint disease but no respiratory symptoms and normal lung function.

\section{PATIENT 2}

In October 1990 a 58 year old man with a 25 year history of seropositive rheumatoid arthritis was referred for assessment of dyspnoea. In November 1989, after he had developed rheumatoid-vasculitis ulceration of his legs, he was started on methotrexate $10 \mathrm{mg} /$ week (total dose $430 \mathrm{mg}$ ).

Two months before presentation he developed a non-productive cough associated with a coryza type illness. Despite antibiotics he deteriorated and became increasingly breathless.

On examination he was afebrile and dyspnoeic with minimal activity. His pulse was $80 / \mathrm{min}$ regular and blood pressure $120 / 70$ $\mathrm{mm} \mathrm{Hg}$. Examination of the chest revealed scattered inspiratory crepitations at both lung bases. The results of arterial blood gas analysis (FIO $21 \%$ ) were: $\mathrm{pH} 7 \cdot 42, \mathrm{PaCO}_{2} 4 \cdot 27 \mathrm{kPa} \mathrm{PaO}$ $11.99 \mathrm{kPa}$. Pulmonary function testing showed that forced expiratory volume in one second $\left(\mathrm{FEV}_{1}\right.$ ) was $2 \cdot 7$ (predicted $\left.2 \cdot 1-3 \cdot 8\right) 1$, forced vital capacity (FVC) $3 \cdot 1$ (predicted $2 \cdot 6-4 \cdot 7$ ) 1 , alveolar volume (VA) 4.2 (predicted 4.9-7.3) l, transfer coefficient (Kco) 0.79 (predicted 1.001.89) $\mathrm{mmol}^{\mathrm{min}}{ }^{-1} \mathrm{kPa}^{-1} \mathrm{l}^{-1}$. The chest radiograph showed diffuse interstitial infiltration.

Methotrexate induced pneumonitis was considered likely and he was advised to discontinue methotrexate and to report any subsequent deterioration without delay.

Four days later he presented with increasing dyspnoea. On examination he was cyanosed and dyspnoeic at rest with basal inspiratory creptitations. The haemoglobin concentration was $13.0 \mathrm{~g} / \mathrm{dl}$ and white blood cells $12.7 \times 10^{9} / 1$ with no eosinophilia. The results of arterial blood gas analysis $\left(\mathrm{FIO}_{2} 21 \%\right)$ were: $\mathrm{pH} 7 \cdot 45$, $\mathrm{PaCO}_{2} 4.02 \mathrm{kPa}, \mathrm{PaO}_{2} 5 \cdot 18 \mathrm{kPa}$. A repeat chest radiograph showed increased interstitial shadowing. Cultures of sputum and blood samples were negative and serological tests on convalescent phase serum showed no rise in titres of antibodies to atypical agents.

Ampicillin and hydrocortisone succinate (200 mg six hourly) were administered intravenously with oral prednisolone $60 \mathrm{mg}$ daily.

By the fourth day he had considerably improved and oxygen saturation was consistently above $95 \% \quad\left(\mathrm{FIO}_{2} 28 \%\right)$. Ampicillin and hydrocortisone were discontinued and oral prednisolone continued. $\mathrm{He}$ was discharged after 12 days taking prednisolone $30 \mathrm{mg}$ daily, which was tailed off over the subsequent two months.

When reviewed four months later he was symptom free, though troubled by a recurrence of articular symptoms. A chest radiograph and results of repeat pulmonary function tests were normal.

\section{PATIENT 3}

In November 1988 a 67 year old woman with a 15 year history of seropositive rheumatoid 
arthritis was admitted with a short history of dyspnoea.

Intramuscular gold injections and chloroquine had been of limited value and she continued to have symptoms despite oral prednisolone. In August 1988 she was started on methotrexate $10 \mathrm{mg} /$ week (total dose $130 \mathrm{mg}$ ), with moderate symptomatic improvement. In the two weeks before admission she became increasingly dyspnoeic. A chest radiograph showed diffuse interstitial and alveolar infiltration.

On examination she was cyanosed and dyspnoeic at rest. Her temperature was $39 \cdot 0^{\circ} \mathrm{C}$, pulse $60 / \mathrm{min}$, and blood pressure $105 / 70$ $\mathrm{mm} \mathrm{Hg}$. Examination of her chest indicated harsh inspiratory creptitations throughout both lung fields.

The haemoglobin concentration was $8.9 \mathrm{~g} / \mathrm{dl}$ and white blood cells $6.6 \times 10^{9} / 1$, with $12 \%$ eosinophils. The erythrocyte sedimentation rate was $110 \mathrm{~mm}$ in the first hour. The results of arterial blood gas analysis $\left(\mathrm{FIO}_{2} 40 \%\right)$ were: $\mathrm{pH}$ $7 \cdot 42, \mathrm{PaCO}_{2} 3 \cdot 7 \mathrm{kPa}, \mathrm{PaO}_{2} 7 \cdot 21 \mathrm{kPa}$. Cultures of sputum and blood samples were negative and serological tests on acute and convalescent phase serum showed no rise in titres of antibodies to atypical agents.

Methotrexate was stopped and broad spectrum antibodies were administered intravenously with oral prednisolone $100 \mathrm{mg}$ daily. Her condition thereafter rapidly improved with both clinical and radiological resolution. She returned to the referring hospital after 10 days taking prednisolone $30 \mathrm{mg}$ daily, which was tailed off over two months.

When reviewed two months later she was symptom free and her chest radiograph normal.

\section{PATIENT 4}

In December 1990 a 75 year old woman with an 11 year history of seropositive rheumatoid arthritis was admitted with dyspnoea. In August 1988 she had been started on methotrexate $5 \mathrm{mg} /$ week (total dose $600 \mathrm{mg}$ ), with an excellent clinical response. Two months before admission she developed a non-productive cough, fever, and increasing dyspnoea, which had progressed despite antibiotics.

On admission she was cyanosed and dyspnoeic at rest. She was afebrile. Her pulse was $120 / \mathrm{min}$ and blood pressure $150 / 80 \mathrm{~mm} \mathrm{Hg}$. Examination of the cest indicated late inspiratory crepitations throughout both lung fields.

The haemoglobin concentration was $10.0 \mathrm{~g} /$ dl and white blood cells $24.5 \times 10^{9} / 1$, with eosinophilia. The erythrocyte sedimentation rate was $87 \mathrm{~mm}$ in the first hour. The results of arterial blood gas analysis $\left(\mathrm{FrO}_{2} 21 \%\right)$ were: $\mathrm{pH}$ $7 \cdot 5, \mathrm{PaCO}_{2} 5 \cdot 3 \mathrm{kPa}, \mathrm{PaO}_{2} 7 \cdot 1 \mathrm{kPa}$. The chest radiograph showed bilateral interstitial and alveolar infiltrates, affecting predominantly the upper lobes (fig 2A). Cultures of sputum and blood samples were negative and serological tests on convalescent phase serum showed no rise in titres of antibodies to atypical agents.

Methotrexate was stopped and she was started on prednisolone $40 \mathrm{mg}$ daily. There was
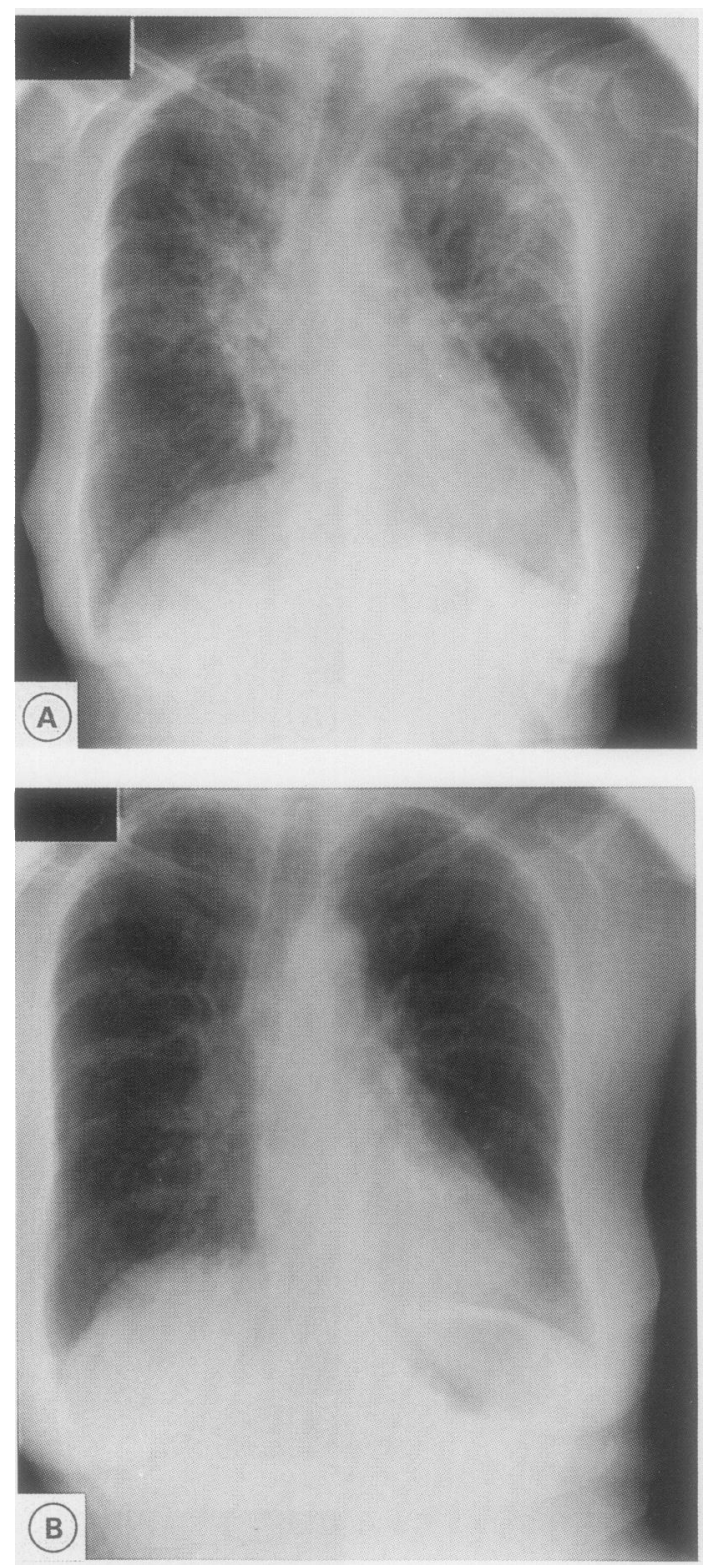

Figure 2 Case 4: Radiological appearances ( $A$ ) at admission and $(B)$ three months after discharge.

considerable clinical and radiological resolution over the next two weeks and she was discharged on a reducing course of corticosteroids. By three months she was symptom free. A chest radiograph confirmed radiological resolution (fig $2 \mathrm{~B}$ ).

\section{PATIENT 5}

In March 1991 a 76 year old man with an 11 year history of seropositve rheumatoid arthritis was admitted with cough and increasing dyspnoea. In November 1990 he was started on methotrexate $10 \mathrm{mg} /$ week (total $180 \mathrm{mg}$ ). A marginal response was observed.

Two months before admission he had noted sweats, fever, and general malaise associated with anorexia and weight loss. Ten days before admission he had developed a non-productive cough with increasing dyspnoea.

Other medications included prednisolone $5 \mathrm{mg}$ daily, tetracosactrin $2 \mathrm{mg} /$ week by intramuscular injection, azapropazone $600 \mathrm{mg}$ twice daily, glibenclamide $5 \mathrm{mg}$ daily, and atenolol $50 \mathrm{mg}$ daily. 
On examination he was dyspnoeic at rest. He was afebrile. His pulse rate was $80 / \mathrm{min}$ regular and blood pressure $130 / 90 \mathrm{~mm} \mathrm{Hg}$. Examination of the chest indicated scattered inspiratory crepitations at both bases.

The haemaglobin concentration was $11.3 \mathrm{~g} /$ $\mathrm{dl}$ and white blood cells $9 \cdot 1 \times 10^{9} / 1 \mathrm{~s}$, with no eosinophilia. The results of arterial blood gas analysis $\left(\mathrm{FIO}_{2} 21 \%\right.$ ) were: $\mathrm{pH} 7 \cdot 46, \mathrm{PaCO}_{2} 4 \cdot 61$, $\mathrm{PaO}_{2}$ 8 23 . Pulmonary function testing showed that $\mathrm{FEV}_{1}$ was 1.2 (predicted 2.2-3.9) 1, FVC 2.0 (predicted 3.0-5.1) 1 , Kco 0.8 (predicted $0.77-1.67) \mathrm{mmol} \mathrm{min} \mathrm{min}^{-1} \mathrm{kPa}^{-1} \mathrm{l}^{-1}$. The chest radiograph showed diffuse interstitial and alveolar infiltrates. Cultures of sputum and blood samples were negative and serological tests on convalescent phase serum showed no rise in titres of antibodies to atypical organisms.

Methotrexate was stopped and erythromycin $500 \mathrm{mg}$ four times daily was administered by mouth. Serial blood gas determinations and the chest radiograph appearances suggested continued deterioration and on the fourth hospital day prednisolone $40 \mathrm{mg}$ daily was prescribed. Within 72 hours there was considerable clinical and radiological improvement. He was discharged after 30 days taking prednisolone $10 \mathrm{mg}$ daily.

\section{Discussion}

It seems likely that the five patients described had methotrexate induced pneumonitis. This diagnosis, however, can only be made with reasonable confidence retrospectively in the light of the clinical course and negative results of microbiological investigations. At the time of presentation the main differential diagnoses included infection, rheumatoid related alveolitis, and drug induced pneumonitis. The fact that four out of the five patients had constitutional symptoms or fever led to the assumption that their illness could be infective and thus could be treated with antibiotics. The subacute onset of symptoms and the diffuse pattern of radiological infiltrates, however, were unusual for a bacterial infection. Atypical and opportunist organisms were considered but the clinical response coincided with the introduction of corticosteroids. Sputum and blood cultures were negative in all patients and the serological tests for atypical organisms showed no rise in antibody titres. The decision to undertake bronchoalveolar lavage may be necessary if there is clinical deterioration and diagnostic uncertainty persists. Its potential usefulness must be balanced against the fact that these patients were severely hypoxic and in the one patient who had bronchoscopy elective intubation and assisted ventilation were necessary. Samples obtained at lavage were negative for Pneumocystis carinii and fungi.

Patients with rheumatoid arthritis may develop diffuse interstitial lung disease unrelated to any medication. ${ }^{7}$ The onset is usually insidious with breathlessness as the main presenting feature. ${ }^{8}$ It would be unusual for the disease to evolve as rapidly as that seen in our patients. The most convincing evidence, however, that their alveolitis was not related to rheumatoid arthritis is the gratifying response to corticosteroids and the fact that the patients remained well from a respiratory viewpoint after the steroids had been stopped.

The clinical presentation of methotrexate induced pneumonitis is usually subacute and dominated by constitutional symptoms, including headache, malaise, and fever. These may persist for weeks or months before the onset of respiratory symptoms heralded by dry cough and dyspnoea. The early symptoms are often insidious, though in some instances may advance rapidly. For example, in patient 2 extreme dyspnoea and hypoxia were observed over 72 hours. Similarly, in patient 1 relentless deterioration was observed after admission and ventilatory support was required. The findings from clinical examination are generally nonspecific. A rash has been reported in up to $16 \%$ of cases of pneumonitis associated with high dose methotrexate for malignant disease. ${ }^{4}$ Fever, dyspnoea, and inspiratory crepitations have been consistently reported. Mild neutrophil leucocytosis has been observed in about $30 \%$ of cases. Although eosinophilia has been reported, ${ }^{4}$ it appears to be unusual with the low dose regimen. Radiological appearances are non-specific and usually consist of bilateral interstitial infiltrates, often with alveolar shadowing. Transient hilar lymphadenopathy has been reported. ${ }^{9}$ Although usually diffuse, the radiological abnormalities may be confined initially to the lower lobes ${ }^{5}$ or even to one lung. 9 The radiological appearances in patient 4 were somewhat unusual as the infiltrates were predominately in the upper lobes.

The role of open lung biopsy in the management of methotrexate induced pneumonitis is uncertain as the histological changes are non-specific, though consistent with drug induced pneumonitis. Findings include an interstitial mononuclear cell infiltrate associated with a variable degree of fibrosis. Multinucleated giant cells, non-caseating granulomas, and eosinophilic infiltrates have also been reported. ${ }^{59}$ Whereas bronchoscopy and bronchoalveolar lavage may help in excluding infection, cytological examination of lavage fluid is generally unhelpful. There may be an absolute or relative increase in the lymphocyte count but this information is of limited diagnostic value. ${ }^{1011}$

Treatment requires the withdrawal of methotrexate, which of itself may effect clinical and radiological resolution. Nevertheless, as was the case in at least two of our patients, the disease may progress and clinical improvement coincide with the introduction of corticosteroid treatment. Such observations have prompted treatment with corticosteroids when the diagnosis seems at all likely. No large scale trials have examined the efficacy of corticosteroids in methotrexate induced pneumonitis but reports throughout the literature attest to their value. It has been suggested that a limited controlled trial is warranted, though we believe that this would be inappropriate in a life threatening condition. ${ }^{12}$ Full supportive measures, including assisted ventilation, is indicated in patients who are critically ill because the ultimate prognosis is good. 
The mechanism of methotrexate induced pneumonitis is uncertain. Some observations have suggested that it may represent an acute hypersensitivity reaction. The presentation with fever and eosinophilia is consistent with the hypersensitivity reaction and is supported by the finding in alveolar lavage fluid of lymphocytic alveolitis. The exact subpopulation of lymphocytes affected is not clear. One study ${ }^{11}$ reported an increase in OKT4 (helper) cells similar to that seen in sarcoidosis ${ }^{13}$ whereas another reported an increase in OKT ${ }^{10}$ (suppressor) cells consistent with hypersensitivity pneumonitis ${ }^{11}$ - for example, in response to gold or organic antigen. ${ }^{1314}$ Further evidence of an immunological mechanism is provided by the reported release of a lymphokine, leucocyte inhibitory factor, from peripheral blood lymphocytes of patients with methotrexate induced pneumonitis. ${ }^{15}$ Finally, the often dramatic response to corticosteroids supports an immune mediative phenomenon. The spontaneous remission during treatment, ${ }^{4}$ however, and reports that pulmonary toxicity may not recur after rechallenge remain to be explained. ${ }^{1617}$

As methotrexate has been shown to accumulate preferentially in the lung, ${ }^{18}$ and clinical resolution may follow dose reduction, ${ }^{19}$ it has been suggested that a direct cytotoxic action may be important in some instances. ${ }^{4}$ Acute pulmonary toxicity appears, however, to be unrelated to either the dose or the duration of treatment. One important variable appears to be the frequency of administration since patients receiving daily or even weekly doses have a higher risk of toxicity than those receiving the drug less frequently. ${ }^{20}$

Two recent prospective studies have addressed the incidence of pulmonary toxicity during low dose methotrexate treatment for active rheumatoid arthritis. Hanrahan et $a l^{21}$ described one such case from a cohort of 128 patients followed for up to four years, and Furst et $a l^{22}$ reported no instances of acute pneumonitis from 45 patients during a treatment period extending over three years. Retrospective analysis based on several series, however, would suggest an incidence of 3$5.5 \% .{ }^{9162324}$ The five cases described here are derived from a cohort of 43 patients prescribed low dose methotrexate over the previous three years, representing an overall incidence of almost $12 \%$. The Committee on Safety of Medicines (personal communication) has received eight reports of pneumonitis associated with methotrexate.

Although low dose methotrexate has been used for over 30 years in the management of psoriasis there have been relatively few reports of acute pulmonary toxicity. ${ }^{45-30}$ Likewise, the incidence of pulmonary toxicity in patients with psoriasis remains uncertain, though Nifors ${ }^{31}$ reports an incidence of $2 \cdot 4 \%$ over an average follow up of three years, lending support to suggestions that rheumatoid patients may be at particular risk of methotrexate lung disease. ${ }^{232}$

Methotrexate represents an important advance in the management of refractory rheumatoid arthritis, where a gratifying clinical response may be observed in selected patients. Accordingly, it is disappointing that, despite low dose regimens, methotrexate may be associated with acute life threatening pneumonitis. We would suggest that before starting treatment patients should have a full clinical, radiological, and physiological assessment for detection of occult lung disease. Further prospective studies are required to examine both the incidence of acute pneumonitis during low dose treatment and potential risk factors for its development.

1 Thompson RN, Watts C, Edelmen J, Esdaile J, Russell AS A controlled two-centre trial of parenteral methotrexate therapy for refractory rheumatoid arthritis. J Rheumatol 1984;11:760-3.

2 Weinblatt ME, Coblyn JS, Fox DA, Fraser PA, Holdsworth DE, Glass DN, et al. Efficacy of low-dose methotrexate in rheumatoid arthritis. N Engl J Med 1985;312:818-22.

3 Williams HJ, Willkens RF, Samuelson CO, Alarcòn GS Guttadauria N, Yareoro C, et al. Comparison of low-dose oral pulse methotrexate and placebo in the treatment of rheumatoid arthritis. A controlled clinical trial. Arthr Rheum 1985;28:721-730.

4 Sostman HD, Matthey RA, Putman CE, Walker-Smith GJ. Methotrexate-induced pneumonitis. Medicine 1976; 55:371-88.

5 Cannon GW, Ward JR, Clegg DO, Samuelson CO Jr Abbott TM. Acute lung disease associated with low-dose pulse methotrexate therapy in patients with rheumatoid arthritis. Arthr Rheum 1983;26:1269-74.

6 Engelbrecht JA, Calhoon SL, Scherrer JJ. Methotrexate pneumonitis after low-dose therapy for rheumatoid arthritis. Arthr Rheum 1983;26:1275-8.

7 Roschmann RA, Rothenberg J. Pulmonary fibrosis in rheumatoid arthritis: a review of clinical features and therapy. Semin Arthr Rheum 1987;16:174-85.

8 Sheil WC, Prete PE. Pleuropulmonary manifestations of rheumatoid arthritis. Semin Arthr Rheum 1984;13:235-43.

9 St Clair EW, Rice JR, Synderman R. Pneumonitis complicating low-dose methotrexate therapy in rheumatoid arthritis. Arch Intern Med 1985;145:2035-8.

10 Akoun GM, Mayaud CM, Touboul JL, Denis MF Milleron BJ, Perrot JY. Use of bronchoalveolar lavage in the evaluation of methotrexate lung disease. Thorax 1987;42:652-5.

11 White DA, Rankin JA, Stover DE, Gellene RA, Gupta S Methotrexate pneumonitis: Bronchoalveolar findings suggest an immunologic disorder. Am Rev Respir Dis 1989; gest an immur

12 Cooper AD Jr, White DA, Matthay RA. State of the art drug induced pulmonary disease. Part 1: Cytotoxic drugs. Am Rev Respir Dis 1986;133:321-40.

13 Hirata T, Nagai S, Oshima S, Izumi T. Comparative study of T-cell subsets in BAL fluid in patients with hypersensitivity pneumonitis and sarcoidosis [abstract]. Chest 1982;82(suppl):232.

14 Ettensohn DB, Roberts NJ, Condemi JJ. Broncho-alveolar lavage in gold lung. Chest 1984;85:569-70.

15 Akoun GM, Gauthier-Rahman S, Mayaud CM, Touboul JL, Denis MF. Leucocyte migration inhibition in methotrexate-induced pneumonitis. Chest 1987;91:96-9.

16 Carson CW, Cannon GW, Egger MJ, Ward JR, Clegg DO Pulmonary disease during the treatment of rheumatoid arthritis with low dose pulse methotrexate. Semin Arthr Rheum 1987;16:186-95.

17 Robbins KM, Gribetz I, Strauss L, Leonidas JC, Sander $M$. Pneumonitis in acute lymphatic leukaemia durin methotrexate therapy. J Pediatr 1973;82:84-8.

18 Anderson LL, Collins GJ, Ojima Y. A Study of the distribution of methotrexate in human tissues and tumours. Cancer Res 1970;30:1344-8.

19 Clarysse AM, Cathey WJ, Cartwright GE, Wintrobe MM Pulmonary disease complicating intermittent therapy with methotrexate. JAMA 1969;209:1861-4.

20 Nesbit M, Krivit W, Heyn R, Sharp H. Acute and chronic effects of methotrexate on hepatic, pulmonary and skeletal systems. Cancer 1979;37:1048-54.

21 Hanrahan PS, Acrivens GA, Russell AS. Prospective long term follow-up of methotrexate therapy in rheumatoid arthritis: toxicity, efficacy and radiological progression. $\mathrm{Br}$ $J$ Rheum 1989;28:147-53.

22 Furst DE, Erikson N, Clute L, Koehnke R, Burmeister LF Kohler JA. Adverse experience with methotrexate during 176 weeks of a longterm prospective trial in patients with rheumatoid arthritis. $J$ Rheumatol 1990;17:1628-35.

23 Kremmer JM, Lee JK. The safety and efficacy of the use of methotrexate in long term therapy for rheumatoid arthritis. Arthr Rheum 1986;29:822-31. 
24 Gispen JG, Alarcon GS, Johnson JJ, Acton RT, Barger BO, Koopman WJ. Toxicity to methotrexate in rheumatoid arthritis. $J$ Rheumatol 1987;14:74-9.

25 Filip DJ, Logue GL, Harle TS, Farrar WH. Pulmonary and hepatic complications of methotrexate therapy of psoriasis. JAMA 1971;216:881-2.

26 From E. Methotrexate pneumonitis in a psoriatic. $\mathrm{Br} \mathrm{J}$ Dermatol 1975;93:107-9.

27 Verdich J, Christensen AL. Pulmonary disease complicating intermittent methotrexate therapy of psoriasis. Acta Dermatol Venereol 1979;59:471-3.

28 Phillips TJ, Jones DH, Baker H. Pulmonary complications following methotrexate therapy. J Am Acad Dermatol 1987;16:373-5.
29 Van Deursen C Th BM, Koudstaal J, Maesen FPV. A patient with methotrexate lung and granulomatous changes in the liver-or just sarcoidosis? Int J Clin Pharmacol Ther Toxicol 1988;26:293-6.

30 Schwartz GF, Anderson ST. Methotrexate induced pneumonitis in a young woman with psoriasis and rheumatoid arthritis. J Rheumatol 1990;17:980.

31 Nyfors A. Benefits and adverse drug experiences during long-term methotrexate treatment of 248 psoriatics. Dan Med Bull 1978;25:208-11.

32 Ridley MG, Wolfe CS, Mathews JA. Life threatening acute pneumonitis during low dose methotrexate treatment for rheumatoid arthritis: a case report and review of the literature. Ann Rheum Dis 1988;47:784-8. 